\title{
Macroinvertebrate Taxonomic and Functional Trait Compositions within Lotic Habitats Affected By River Restoration Practices
}

\author{
J. C. White ${ }^{1}$ M. J. Hill ${ }^{2}$ M. A. Bickerton ${ }^{3} \cdot$ P. J. Wood ${ }^{1}$
}

Received: 18 October 2016 / Accepted: 3 May 2017 / Published online: 17 May 2017

(C) The Author(s) 2017. This article is an open access publication

\begin{abstract}
The widespread degradation of lotic ecosystems has prompted extensive river restoration efforts globally, but many studies have reported modest ecological responses to rehabilitation practices. The functional properties of biotic communities are rarely examined within post-project appraisals, which would provide more ecological information underpinning ecosystem responses to restoration practices and potentially pinpoint project limitations. This study examines macroinvertebrate community responses to three projects which aimed to physically restore channel morphologies. Taxonomic and functional trait compositions supported by widely occurring lotic habitats (biotopes) were examined across paired restored and non-restored (control) reaches. The multivariate location (average community composition) of taxonomic and functional trait compositions differed marginally between control and restored reaches. However, changes in the amount of multivariate dispersion were more robust and indicated greater ecological heterogeneity within restored reaches, particularly when considering functional
\end{abstract}

Electronic supplementary material The online version of this article (doi:10.1007/s00267-017-0889-1) contains supplementary material, which is available to authorized users.

J. C. White

J.White2@lboro.ac.uk

1 Centre for Hydrological and Ecosystem Science, Department of Geography, Loughborough University, Loughborough, Leicestershire, LE11 3TU, UK

2 Institute of Science and the Environment, University of Worcester, Henwick Grove, Worcester WR2 6AJ, UK

3 School of Geography, Earth and Environmental Sciences, University of Birmingham, Edgbaston, Birmingham, B15 2TT, UK trait compositions. Organic biotopes (macrophyte stands and macroalgae) occurred widely across all study sites and supported a high alpha (within-habitat) taxonomic diversity compared to mineralogical biotopes (sand and gravel patches), which were characteristic of restored reaches. However, mineralogical biotopes possessed a higher beta (between-habitat) functional diversity, although this was less pronounced for taxonomic compositions. This study demonstrates that examining the functional and structural properties of taxa across distinct biotopes can provide a greater understanding of biotic responses to river restoration works. Such information could be used to better understand the ecological implications of rehabilitation practices and guide more effective management strategies.

Keywords Habitat enhancement - Invertebrates $\cdot$ Lotic ecosystems $\cdot$ River rehabilitation $\cdot$ Traits

\section{Introduction}

A significant number of river restoration projects aiming to rehabilitate degraded lotic ecosystems have been carried out globally (Ormerod 2004; Bernhardt et al. 2007; Miller et al. 2010; Kail et al. 2015). River restoration practices regularly involve changes to the physical template of fluvial environments, with project aims often centered on promoting a range of habitats capable of supporting heterogeneous biotic assemblages (Palmer et al. 2010). However, evidence from a plethora of studies has highlighted that reinstating a greater degree of habitat heterogeneity in lotic environments 
does not guarantee ecological recovery (e.g., Roni et al. 2008; Miller et al. 2010; Barnes et al. 2013).

Limited ecological responses to river restoration works have been attributed to a multitude of reasons, including socio-economic constraints (Langford and Shaw 2014) and inappropriate spatial scaling of projects (Miller et al. 2010). In addition, restoration schemes are regularly undertaken without the guidance of ecological baseline data, with biomonitoring information often not being collected before or after project implementation (Bernhardt et al. 2007; Kail et al. 2015). Furthermore, various studies have attributed ecologically ineffective rehabilitation projects to prevailing abiotic constraints (e.g., degraded water quality, modified flow regimes) and/or organism dispersal limitations (e.g., Lepori et al. 2005; Jähnig et al. 2010; Tonkin et al. 2014). Palmer et al. (2010) reviewed 78 river restoration projects globally and found no association between habitat heterogeneity and the richness of macroinvertebrate taxa, suggesting that existing restoration techniques have been inappropriate in facilitating ecological recovery. However, quantifying changes in taxonomic richness after restoration works may not necessarily be a suitable biological end point (besides being consistently reported within post-project appraisals) and the need to report functional responses to river restoration efforts is being increasingly advocated (e.g., Dolédec et al. 2015; Kail et al. 2015).

The examination of functional traits (the biological properties and ecological preferences of organisms) is often overlooked within river restoration post-project appraisals (Kail et al. 2015). Processing such information alongside traditional taxonomic-based approaches and quantifying biotic differences between restored and non-restored (control) sites within univariate and multivariate contexts enhances the amount of ecological information available from post-project appraisals. Univariate taxonomic responses allow target organisms (e.g., non-native taxa) to be examined, while individual traits may infer causal mechanisms underpinning biotic responses to river restoration practices by highlighting the sensitivity of specific faunal properties (e.g., Jähnig and Lorenz 2008; Tullos et al. 2009). Multivariate analysis of taxonomic and trait compositions allows different types of community responses to be examined. Within lotic environments, shifts in the multivariate location (the average community composition) of biotic communities are often the result of large-scale environmental variables which have similar environmental implications across an entire river catchment or region (Poff 1997). However, the amount of multivariate dispersion is likely to be more sensitive to small-scale variables which have localized biotic implications, such as the presence of different habitats between study sites (see Heino et al. 2012).

Lotic "biotopes" comprise various types of mineralogical coverings (e.g., gravel and sand substrate patches) and organic habitats (e.g., macroalgae and macrophyte stands) which arise through hydrological, hydraulic, and geomorphological forces (Armitage et al. 1995; Storey and Lynas 2007). The term "biotopes" (sensu Demars et al. 2012) is used in this study as an ecological equivalent to "microhabitats" (sensu Frissell et al. 1986), "mesohabitats" (sensu Tickner et al. 2000) or "functional habitats" (sensu Harper et al. 1998). Various studies have reported that biotopes support distinct faunal compositions (e.g., Harper et al. 1992, 1998; Buffagni et al. 2000; Storey and Lynas 2007) and the recognition of such habitats have underpinned river conservation strategies (Tickner et al. 2000; Harvey and Clifford 2008). In addition, they have been used to appraise biotic responses to different anthropogenic influences within lotic environments including flow regulation (Armitage and Pardo 1995; Storey and Lynas 2007) and river restoration practices (Verdonschot et al. 2016). However, biotope controls on the functional composition of macroinvertebrate communities have not been widely explored within lotic ecosystems, but could offer further ecological information which could underpin river management strategies (see Demars et al. 2012).

This study examines macroinvertebrate taxonomic and functional trait responses to three river restoration projects conducted within the River Tame (East and West Midlands, UK), a historically polluted and physically modified catchment. The restoration techniques used on the projects examined in this study are novel within the UK as they involved fashioning multi-channel systems, which has rarely been incorporated within other restoration projects implemented nationwide (see River Restoration Centre 2013). The study aims are to: (i) quantify differences in macroinvertebrate taxonomic and functional trait compositions between control and restored reaches; (ii) examine if the structural and functional attributes of macroinvertebrate communities differ between distinct biotopes supported by control and restored reaches and (iii) evaluate the advantages of utilizing macroinvertebrate functional traits within river restoration post-project appraisals.

\section{Methods}

\section{Study Area and Sites}

The River Tame represents one of the most urbanized fluvial landscapes in the UK (Webster et al. 2001). Watercourses within the catchment have been historically subjected to heavy metal and nutrient pollution, in addition to widespread morphological changes (Beavan et al. 2001; Langford et al. 2010-see Supplementary Material for water quality parameters). Prior to anthropogenic influences, the Tame exhibited a braided planform as a result of 


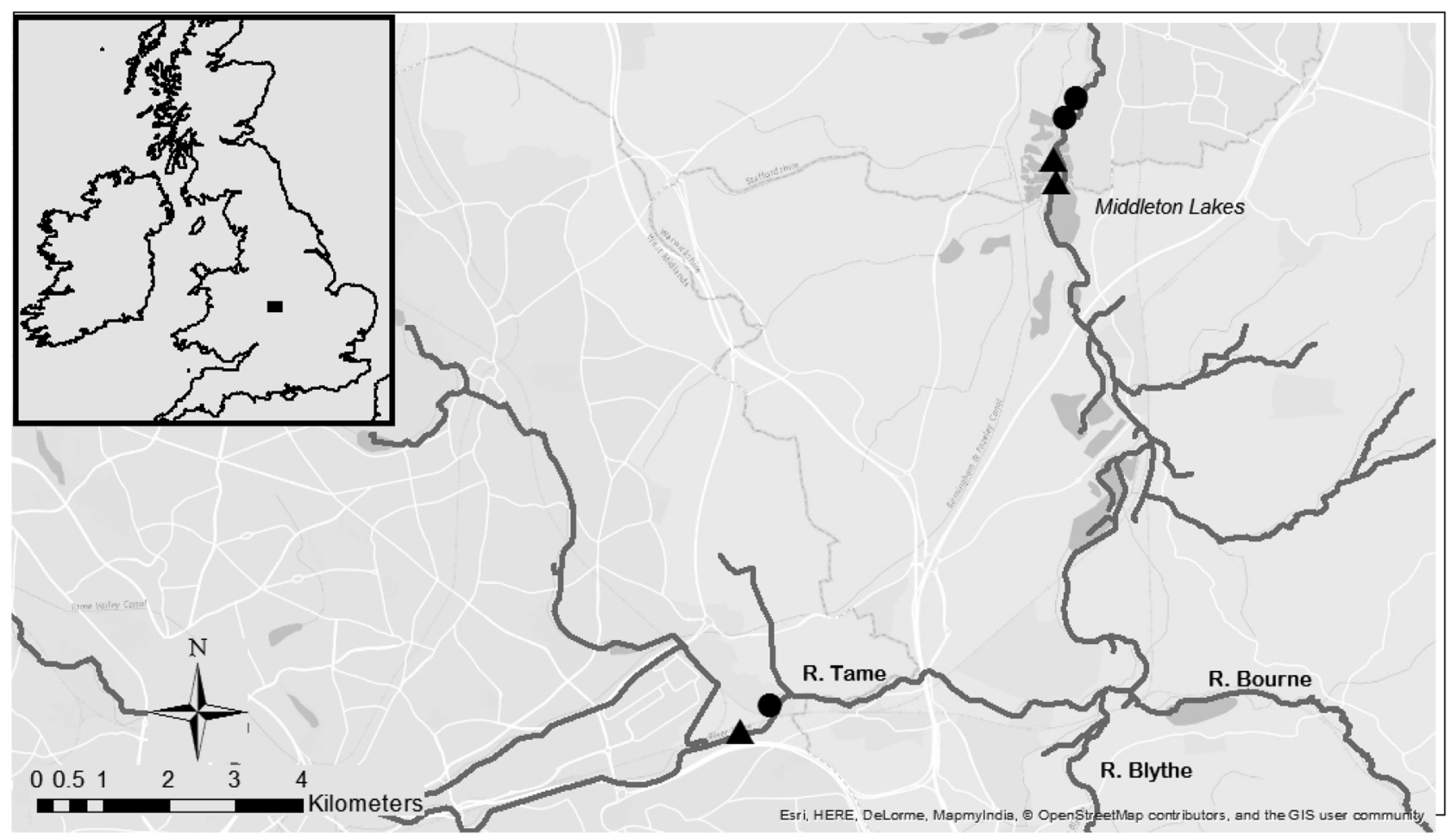

Fig. 1 Study sites across the River Tame. Square $=$ study location, Triangles $=$ control sites, and Circles $=$ restored sites

its sandstone lithology (Ellis et al. 2007), but is now characterized by a single-thread morphology throughout the catchment.

Three restoration schemes were examined which involved reach-scale channel manipulations (project lengths ranging from $253-500 \mathrm{~m}$ ) aiming to reinstate a multichannel planform by widening channels and creating mature vegetated islands that divert flows into separate channels (see Supplementary Material for further information on each project). Restoration works were completed between 7 and 16 years prior to fieldwork being conducted in summer 2014, thus allowing sufficient time for the recolonization and recovery of macroinvertebrate communities. Two of the restoration projects were conducted along adjacent stretches of river (see Fig. 1), but were completed 8 years apart and involved different techniques (with one project also creating mid-channel bars which become inundated at higher flows—see Supplementary Material), so were treated as separate sites in this study. With no prerestoration data being available, a space-time substitution was adopted and each restored reach was paired with a respective non-restored (control) reach situated $<1 \mathrm{~km}$ upstream. While it is recognized that taxa drifting between sites may have influenced biotic differences between control and restored reaches, sampling faunal assemblages from specific habitat units (see below) would provide fundamental information on whether macroinvertebrates colonized distinct biotopes influenced by river restoration practices As a result of widespread historic anthropogenic modifications throughout the River Tame's course, no baseline reference conditions or analogs were available to provide a benchmark for restoration outcomes.

\section{Observations of Biotopes}

Biotopes were pre-defined as distinct in-channel habitat patches that were visually distinguishable from the river bank (Armitage et al. 1995; Demars et al. 2012). Preliminary walkover surveys were conducted to characterize the visually "dominant biotopes" evident within each of the six study reaches, defined herein as those possessing at least three distinct patches (to guide subsequent macroinvertebrate sampling - see below) which collectively dominate the wetted area of the channel (Storey and Lynas 2007). The spatial configuration and prevalence of dominant biotopes were visually mapped onto a river channel outline obtained from Google Earth (2015). This was conducted across the entirety of each study reach to ensure all dominant biotopes were characterized. Mapping the composition of dominant biotopes was not used to quantify habitat heterogeneity per se, but facilitated the identification of widely occurring habitat patches which are artifacts of hydraulic and geomorphological forces (Kemp et al. 1999) influenced by the restoration activities examined in this study. Rare biotopes (including silt patches and woody debris) were not included in the final analyses due to insufficient numbers of replicate samples. Subsequently, six dominant 
biotopes were identified for sampling, with macroalgae, "Ranunculus. sp" (a fine-leaved, submerged macrophyte) and "Sparganium emersum" (a broad-leaved, submerged macrophyte) representing the three dominant organic biotopes. Gravel, sand and a mixture of these substrates (whereby gravel clasts were present within a sand matrix) were the three dominant mineralogical biotopes surveyed.

\section{Macroinvertebrate Sampling}

Macroinvertebrates were collected using 15-s kick samples from separate patches of all dominant biotopes observed within each study reach, with three replicate samples being taken (sensu Tickner et al. 2000). A total of 69 samples were collected, with a smaller number $(n=24)$ being collected

Table 1 Macroinvertebrate functional traits examined within this study

\begin{tabular}{|c|c|c|c|c|c|}
\hline Grouping feature & Trait & Code & Grouping feature & Trait & Code \\
\hline \multirow[t]{7}{*}{$\begin{array}{l}\text { Maximum potential } \\
\text { size }\end{array}$} & $\leq 0.25 \mathrm{~cm}$ & Size.1 & $\begin{array}{l}\text { Locomotion and substrate } \\
\text { relation }\end{array}$ & Flier & Locomotion.1 \\
\hline & $>0.25-0.5 \mathrm{~cm}$ & Size. 2 & & Surface swimmer & Locomotion. 2 \\
\hline & $>0.5-1 \mathrm{~cm}$ & Size. 3 & & Full water swimmer & Locomotion. 3 \\
\hline & $>1-2 \mathrm{~cm}$ & Size. 4 & & Crawler & Locomotion. 4 \\
\hline & $>2-4 \mathrm{~cm}$ & Size. 5 & & Burrower & Locomotion.5 \\
\hline & $>4-8 \mathrm{~cm}$ & Size. 6 & & Interstitial & Locomotion.6 \\
\hline & $>8 \mathrm{~cm}$ & Size.7 & & Temporarily attached & Locomotion. 7 \\
\hline \multirow[t]{2}{*}{ Life-cycle duration } & $\leq 1$ year & Life-cycle.1 & & Permanently attached & Locomotion. 8 \\
\hline & $>1$ year & Life-cycle. 2 & Food consumed & Microorganisms & Food.1 \\
\hline \multirow[t]{3}{*}{ Voltinism } & $<1$ & Voltinism.1 & & Detritus $<1 \mathrm{~mm}$ & Food.2 \\
\hline & 1 & Voltinism.2 & & Dead plant $\geq 1 \mathrm{~mm}$ & Food.3 \\
\hline & $>1$ & Voltinism.3 & & Living microphytes & Food.4 \\
\hline \multirow[t]{4}{*}{ Aquatic stages } & Egg & Stage.1 & & Living macrophtyes & Food.5 \\
\hline & Larva & Stage. 2 & & Dead animal $\geq 1 \mathrm{~mm}$ & Food.6 \\
\hline & Nymph & Stage. 3 & & Living microinvertebrates & Food.7 \\
\hline & Adult & Stage. 4 & & Living macroinvertebrates & Food.8 \\
\hline \multirow[t]{8}{*}{ Reproduction strategy } & Ovoviviparity & Reproduction.1 & & Vertebrates & Food.9 \\
\hline & Isolated, free eggs & Reproduction.2 & Feeding group & Absorber & Feeding.1 \\
\hline & Isolated, cemented eggs & Reproduction.3 & & Deposit feeder & Feeding. 2 \\
\hline & Clutches, cemented & Reproduction. 4 & & Shredder & Feeding. 3 \\
\hline & Clutches, free & Reproduction.5 & & Scraper & Feeding.4 \\
\hline & Clutches, in vegetation & Reproduction.6 & & Filter-feeder & Feeding. 5 \\
\hline & Clutches, terrestrial & Reproduction.7 & & Piercer & Feeding.6 \\
\hline & Asexual & Reproduction.8 & & Predator & Feeding.7 \\
\hline \multirow[t]{4}{*}{ Dispersal strategy } & Aquatic passive & Dispersal.1 & & Parasite & Feeding.8 \\
\hline & Aquatic active & Dispersal.2 & Substrate preference & Coarse substrates & Substrate.1 \\
\hline & Aerial passive & Dispersal.3 & & Gravel & Substrate. 2 \\
\hline & Aerial active & Dispersal.4 & & Sand & Substrate. 3 \\
\hline \multirow[t]{5}{*}{ Resistance form } & Eggs/statoblasts & Resistance.1 & & Silt & Substrate. 4 \\
\hline & Cocoons & Resistance. 2 & & Macrophytes & Substrate. 5 \\
\hline & $\begin{array}{l}\text { Housings against } \\
\text { desiccation }\end{array}$ & Resistance. 3 & & Microphytes & Substrate.6 \\
\hline & Diapause/dormancy & Resistance. 4 & & Twigs/roots & Substrate.7 \\
\hline & None & Resistance. 5 & & Organic detritus & Substrate. 8 \\
\hline \multirow[t]{5}{*}{ Respiration method } & Tegument & Respiration.1 & & Mud & Substrate. 9 \\
\hline & Gill & Respiration.2 & Velocity preference & Null & Velocity.1 \\
\hline & Plastron & Respiration. 3 & & Slow & Velocity.2 \\
\hline & Spiracle & Respiration.4 & & Medium & Velocity.3 \\
\hline & Hydrostatic vesicle & Respiration.5 & & Fast & Velocity.4 \\
\hline
\end{tabular}


from control reaches due to a reduced number of dominant biotopes being present compared to restored reaches $(n=$ 45). Samples were preserved in $70 \%$ ethanol in the field and identified to family-level in the laboratory, with the exception of Oligochaeta which were identified as such.

\section{Functional Traits}

Macroinvertebrate functional traits in this study were derived from a database initially developed in France, but which is applicable to other European freshwater systems (UsseglioPolatera et al. 2000; Tachet et al. 2010). For comparability with other studies, the nomenclature of functional traits is reported herein by their "grouping features" and "traits" (as outlined by Schmera et al. 2015). Grouping features represent a functional trait category (e.g., "life-cycle duration" and "maximum body size"), while traits represent the modalities residing within these (e.g., life-cycle duration - " $\leq 1$ year", " $>1$ year"; maximum body size- $\leq 0.25 \mathrm{~cm}$ ", " $\geq 8 \mathrm{~cm}$ "). The functional trait database employs a "fuzzy-coding" approach, whereby macroinvertebrate affinities for individual traits range from zero (indicating no affinity) to three or five (indicating strong affinity-the maximum value depending on the level of information available in existing literaturesee Chevene et al. 1994; Tachet et al. 2010). Information within the original traits database is typically available at species- or genus-level and the processing of traits for use within this research involved a series of steps: (i) removing non-UK taxa (guided by Davies and Edwards 2011) from the initial database (sensu Demars et al. 2012), as well as those not observed within this study; (ii) standardizing each grouping feature so that traits summed to 1 (thus ensuring equal taxonomic weighting); (iii) averaging values to match the taxonomic resolution of faunal information available within this study and then standardizing (as above) to account for taxa expressing zero affinity scores across all traits within a specific grouping feature; (iv) multiplying these values by $\ln (\mathrm{x}+1)$ transformed community abundances (see Schmera et al. 2014) to create a trait-abundance array; (v) averaging each trait across all sampled taxa and standardizing (as above) to account for between reach abundances (Gayraud et al. 2003; Demars et al. 2012). Thirteen grouping features were analyzed (Table 1), with only two characterizing ecological preferences (velocity and substrate) which were selected a priori due to river widening at restored sites modifying the hydraulic conditions and substrate composition of the channel (as opposed to other ecological preferences within the database-see Tachet et al. 2010).

\section{Statistical Analysis}

Prior to analysis, macroinvertebrate community abundances were $\ln (\mathrm{x}+1)$ transformed to ensure consistent comparability with functional trait responses (see step iv in the trait processing procedure above). All analyses were performed using $\mathrm{R}$ version 3.0.2 ( $\mathrm{R}$ Development Core Team 2014). The multivariate composition of macroinvertebrate community abundances (taxonomic) and functional traits comprising control and restored reaches was examined via a "Principal Coordinate Analysis" (PCoA) using a Bray-Curtis dissimilarity index, which was obtained using the "cmdscale" function in the "Vegan" package (Oksanen et al. 2016). Differences in the multivariate location (the position of the community centroid) between all samples from control and restored reaches were statistically tested via a nested "Permutational Multivariate Analysis of Variance" (PERMANOVA-using the "adonis" function; each paired control and restored site was used as a blocking factor in Vegan). The multivariate dispersion of macroinvertebrate communities residing in control and restored reaches was quantified by a "Permutational Analysis of Multivariate Dispersion" (PERMDISP—using the "betadisper" function in the Vegan package). These two sets of analyses were performed on both taxonomic and functional trait compositions. The significance of PERMDISP was determined via an analysis of variance (ANOVA). PERMANOVA and PERMDISP analyses were also repeated on samples only collected from organic biotopes (i.e., excluding macroinvertebrate samples taken from any mineralogical patches) due to the widespread occurrence of these biotopes across both control and restored reaches (see Results). The differences of individual taxa and traits (univariate responses) between control and restored reaches were also examined by performing "Similarity Percentages" (SIMPER) analysis via the "simper" function in Vegan. Taxa exclusively sampled from either control or restored reaches were assessed in terms of their numerical abundance (with those comprising $<1 \%$ of the entire community population being classified as "rare"-sensu Ledger et al. 2009) and the number of samples that they were located within.

Statistical differences in macroinvertebrate compositions between biotopes were examined via a nested PERMANOVA, with each respective pair of control and restored reaches being used as a blocking factor. The alpha-diversity of faunal assemblages supported by each biotope was assessed for both taxonomic and functional trait compositions by calculating the inverse Simpson's diversity (see Oksanen 2016), which was used to account for the fixed number of traits and their lack of independence (Larsen and Ormerod 2010). The beta-diversity of taxonomic and functional trait compositions within each biotope was quantified by calculating the multivariate dispersion (see Anderson et al. 2006) via PERMDISP to indicate the degree of ecological heterogeneity. Graphics for these diversitybiotope associations were prepared using the "ggplot2" package (Wickham and Chang 2016). Linear models were 
a

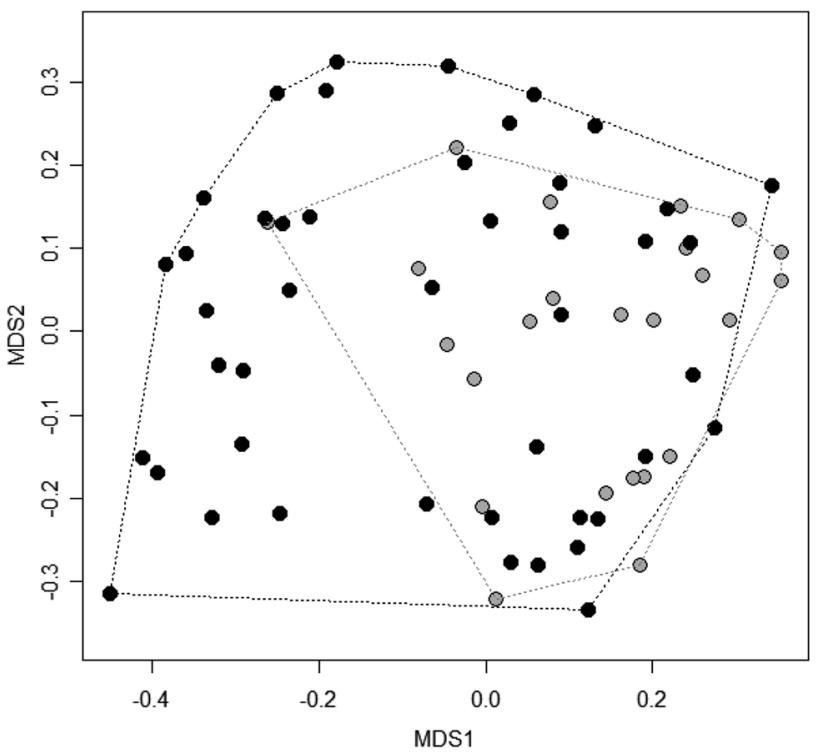

Fig. 2 PCoA plots of macroinvertebrates communities between control and restored reaches for $\mathbf{a}$ taxonomic and $\mathbf{b}$ functional trait compositions. Grey circles $=$ control reaches and black circles $=$ restored

constructed between alpha- and beta-diversity values (dependent variables) and biotopes (independent variable) for both taxonomic and functional trait compositions, whereby model residuals were plotted against fixed values to assess the homogeneity of variances and QuantileQuantile plots were inspected to ensure that models were normally distributed. Subsequently, a one-way ANOVA was performed on each of these models, with a "Tukey's Honest Significant Difference" (THSD) post-hoc comparisons test being performed on those identified as significant $(\alpha=0.05)$. This allowed pair combinations of biotopes supporting significantly different alpha- and beta-diversity values to be identified. Finally, a group-equalized "Indicator Value" (IndVal) analysis was conducted via the "multipatt'"function in the 'indicspecies' package (De Caceres and Jansen 2015) to examine the preferences of specific taxa and traits towards different biotopes and performed across 999 permutations to determine its significance.

\section{Results}

\section{Macroinvertebrate Responses to Restoration Works}

PERMANOVA highlighted that control and restored reaches possessed significantly different multivariate locations for both taxonomic $(F=4.05, p=\leq 0.001)$ and functional trait compositions $(F=5.17, p \leq 0.001)$, but this only accounted for $6 \%\left(r^{2}=0.06\right)$ and $7 \%\left(r^{2}=0.07\right)$ of the statistical variance, respectively. PERMDISP demonstrated

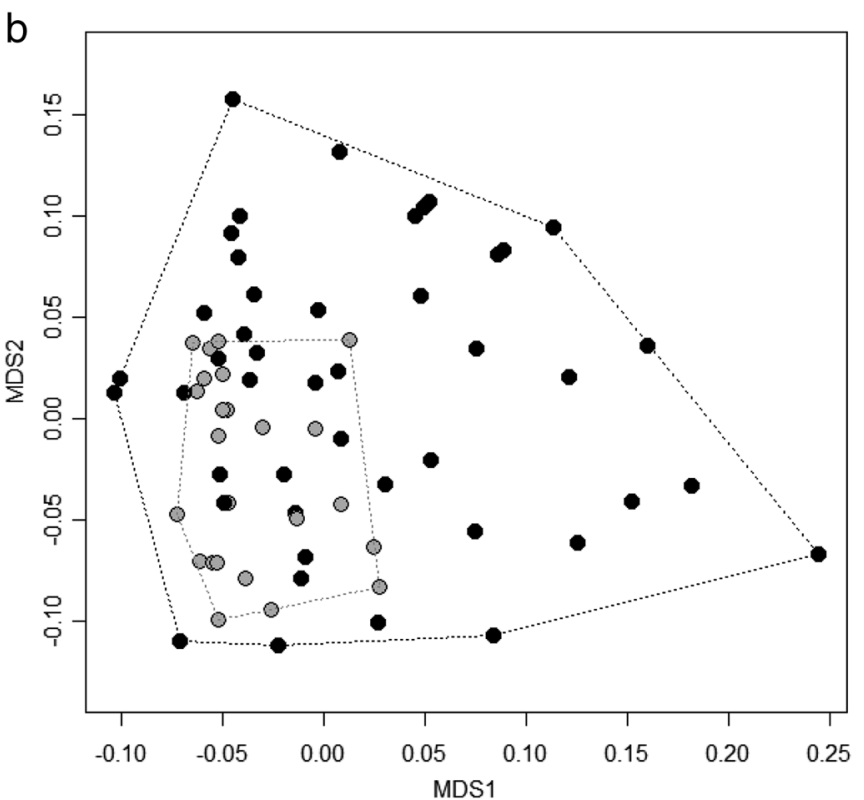

reaches. A convex hull has been drawn to highlight differences in the area of multivariate space occupied by each factor

that the amount of multivariate dispersion differed significantly between samples from control and restored reaches for both taxonomic $(F=13.96, p \leq 0.001)$ and functional trait compositions $(F=16.71, p \leq 0.001)$ and accounted for $17 \%\left(r^{2}=0.17\right)$ and $20 \%\left(r^{2}=0.20\right)$ of the statistical variance, respectively. PCoA plots highlighted subtle shifts in the community centroid between control and restored reaches, with samples from the latter clearly possessing higher levels of multivariate dispersion, most evidently for functional trait compositions (Fig. 2). Analyses conducted on samples taken exclusively from organic biotopes (i.e., with those from mineralogical biotopes being excluded) highlighted that neither the multivariate location or dispersion differed significantly between control and restored reaches for both taxonomic (PERMANOVA: $F=$ $0.93, r^{2}=0.02, p=0.376$; PERMDISP: $F=0.58, r^{2}=$ $0.01, p=0.449$ ) and functional trait compositions (PERMANOVA: $F=1.98, r^{2}=0.04, p=0.054$; PERMDISP: $F$ $=0.95, r^{2}=0.02, p=0.334$ ). SIMPER analysis highlighted 9 macroinvertebrate families (spanning various taxonomic orders) and seven traits (from various grouping features) differed significantly between control and restored reaches (see Table 2). All of these were higher on average at control sites, with the exception of the trait "substrate.3" (community preferences towards sand substrates) which increased on average within restored reaches. Some taxa were unique to restored reaches (Caenidae, Ceratopogonidae, Corixidae, Hydrophilidae, Pediciidae and Tipulidae), while others were only sampled within control sites (Muscidae, Naucoridae, Planariidae, Psychomyiidae); but all of these taxa were 
Table 2 Mean average ( \pm 1 standard deviation) (a) taxa abundances and (b) trait values in control and restored reaches which differed significantly based on SIMPER analysis

\begin{tabular}{|c|c|c|c|c|}
\hline & Taxa/Trait & Control & Restored & $p$-value \\
\hline \multirow[t]{9}{*}{ (a) } & Asellidae & $37.20(58.44)$ & $28.70(54.59)$ & $0.001 * * *$ \\
\hline & Crangonyctidae & $0.73(1.72)$ & $0.63(1.56)$ & $0.025 *$ \\
\hline & Gammaridae & $11.84(20.47)$ & $9.43(15.62)$ & $0.014 *$ \\
\hline & Glossiphoniidae & $1.25(2.75)$ & $0.95(2.6)$ & $0.047 *$ \\
\hline & Muscidae & $0.02(0.14)$ & $0.02(0.12)$ & $0.012 *$ \\
\hline & Naucoridae & $0.02(0.14)$ & $0.02(0.12)$ & $0.012 *$ \\
\hline & Planariidae & $0.02(0.14)$ & $0.02(0.12)$ & $0.02 *$ \\
\hline & Polycentropodidae & $1.08(2.65)$ & $1.14(2.59)$ & $0.044 *$ \\
\hline & Psychomyiidae & $0.02(0.14)$ & $0.02(0.12)$ & $0.013^{*}$ \\
\hline \multirow[t]{7}{*}{ (b) } & Feeding.group. 3 & $0.36(0.015)$ & $0.23(0.020)$ & $0.002 * *$ \\
\hline & Feeding.group. 8 & $0.02(0.003)$ & $0.02(0.001)$ & $0.042 *$ \\
\hline & Food.3 & $0.18(0.007)$ & $0.12(0.009)$ & $0.003 * *$ \\
\hline & Food.9 & $0.02(0.004)$ & $0.01(0.002)$ & $0.029 *$ \\
\hline & Reproduction.1 & $0.42(0.013)$ & $0.29(0.02)$ & $0.049 *$ \\
\hline & Substrate. 3 & $0.08(0.004)$ & $0.11(0.005)$ & $0.036^{*}$ \\
\hline & Substrate. 6 & $0.07(0.003)$ & $0.05(0.003)$ & $0.007 * *$ \\
\hline
\end{tabular}

$* p \leq 0.05 ; * * p \leq 0.01 ; * * * p \leq 0.001$

numerically rare and were only recorded in one sample except for Caenidae (seven samples; Order: Ephemeroptera) and Tipulidae (two samples; Order: Diptera).

\section{Differences in Macroinvertebrate Compositions Between Biotopes}

Control reaches were dominated by organic biotopes in all instances, so that bare patches of mineral substrates were not visible from the river bank (and subsequently not sampled). Restored reaches almost always comprised the same organic biotopes as their respective control reach and additionally included distinct patches of bare mineralogical substrates (as evident from aerial imagery-see Supplementary Material). PERMANOVA highlighted the average community composition values for both taxonomic $(F=$ $4.19, p \leq 0.001)$ and functional trait compositions $(F=$ $4.54, p \leq 0.001)$ differed significantly between dominant biotopes, which explained $25 \%\left(r^{2}=0.25\right)$ and $26 \%\left(r^{2}=\right.$ $0.26)$ of the total statistical variance, respectively. The alpha-diversity of macroinvertebrate taxonomic compositions was typically higher within organic habitats (Fig. 3a) and differed significantly between biotopes (ANOVA: $F=$ 12.62, $p \leq 0.001$ ), accounting for $50 \%$ of the statistical variation $\left(r^{2}=0.50\right)$. This pattern was less pronounced when functional trait responses were considered (Fig. 3b), with no significant difference occurring between the inverse Simpson's diversity value for different biotopes (ANOVA: $\left.F=1.78, r^{2}=0.12, p=0.129\right)$. Sand exhibited the lowest average alpha-diversity values for both forms of biotic information (Fig. 3). THSD highlighted significant differences between the alpha-diversity of taxonomic compositions for all pair combinations of biotopes comprising one organic and one mineralogical habitat. The most highly significant values recorded occurred where alpha-diversity values from different organic biotopes were compared against finer substrates: gravel $(p=0.007-0.036)$, gravel and sand $(p=\leq 0.001-0.003)$ and sand $(p=\leq 0.001)$. Conversely, beta-diversity was highest in sand for both taxonomic (Fig. 3c) and functional trait compositions (Fig. 3d). However, the former displayed comparable degrees of multivariate dispersion between biotopes (accounting for $8 \%$ of the statistical variance $-r^{2}=0.08$ ) and did not differ significantly (ANOVA: $F=1.16, p=0.338$ ), compared to the latter which differed significantly (ANOVA: $F=3.61$, $p=0.006)$ and explained $22 \%$ of the statistical variance $\left(r^{2}\right.$ $=0.22$ ). THSD demonstrated that the beta-diversity of functional trait compositions within sand samples differed significantly from Ranunculus. sp $(p=0.002), S$. Emersum $(p=0.035)$ and macroalgae $(p=0.013)$, while all other pairwise comparisons of biotopes were not significant. IndVal analysis indicated eight macroinvertebrate families and traits were associated with specific combinations of biotopes (see Table 3). Organic biotopes were associated with a higher number of ecological responses compared to mineralogical patches. S. emersum was the only individual biotope found to be associated with a specific macroinvertebrate response ("Respiration.3"- the trait denoting fauna possessing plastron respiration) and this macrophyte was present within six out of seven biotope combinations comprising significant ecological preferences. Sand was associated with the lowest number of macroinvertebrate taxa and traits. None of the taxa unique to control or restored reaches were significantly associated with specific biotopes. Caenidae (Order: Ephemeroptera) and Tipulidae (Order: Diptera the two taxa that were unique to restored reaches and found in more than one sample) were collected from one and zero patches of bare substrate, respectively.

\section{Discussion}

\section{Ecological Responses to River Restoration Projects}

River restoration projects often involve physically altering channel morphologies (channel shape, size and configuration) to enhance the quality and quantity of instream habitats. This is evident in the UK where the national "River Restoration Centre" has compiled a handbook of restoration techniques which outlines various methods and case studies on morphologically rehabilitating rivers subject to a range 
a

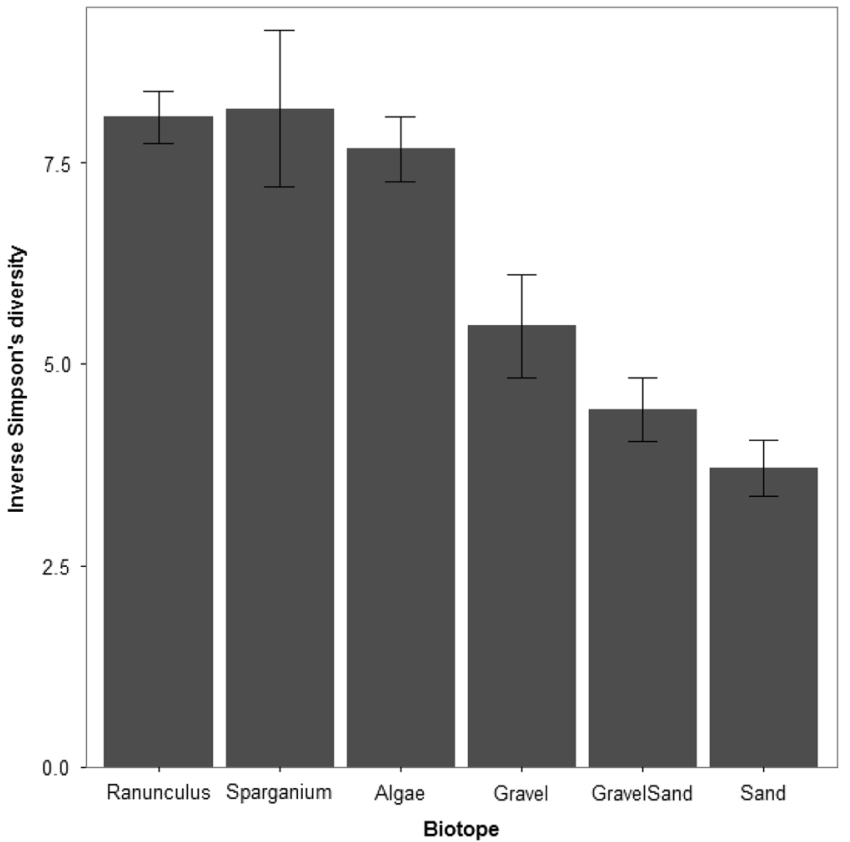

C

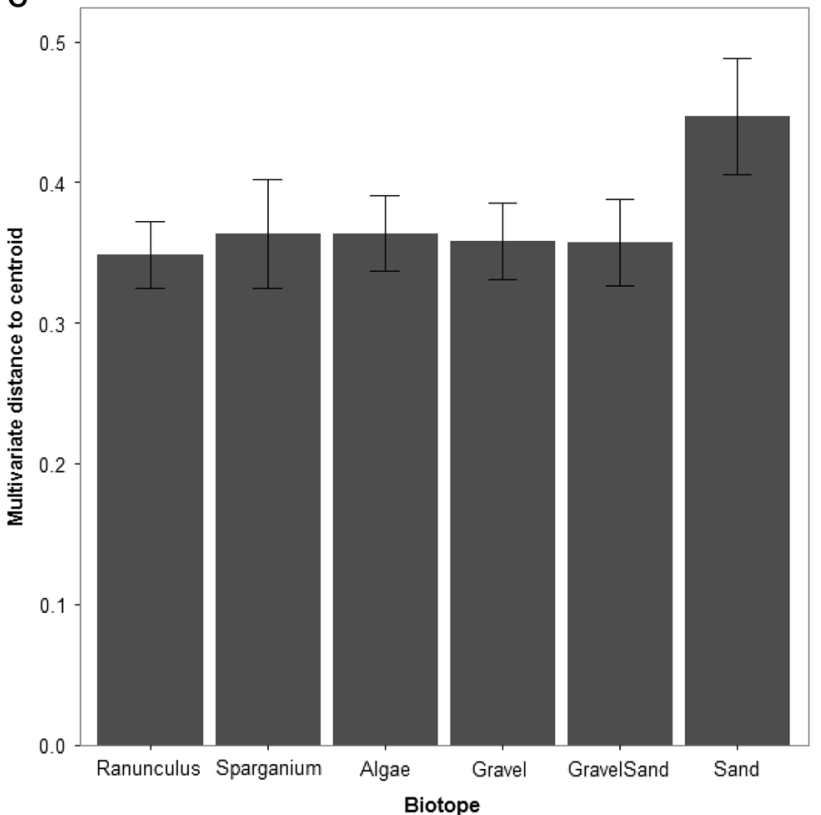

b

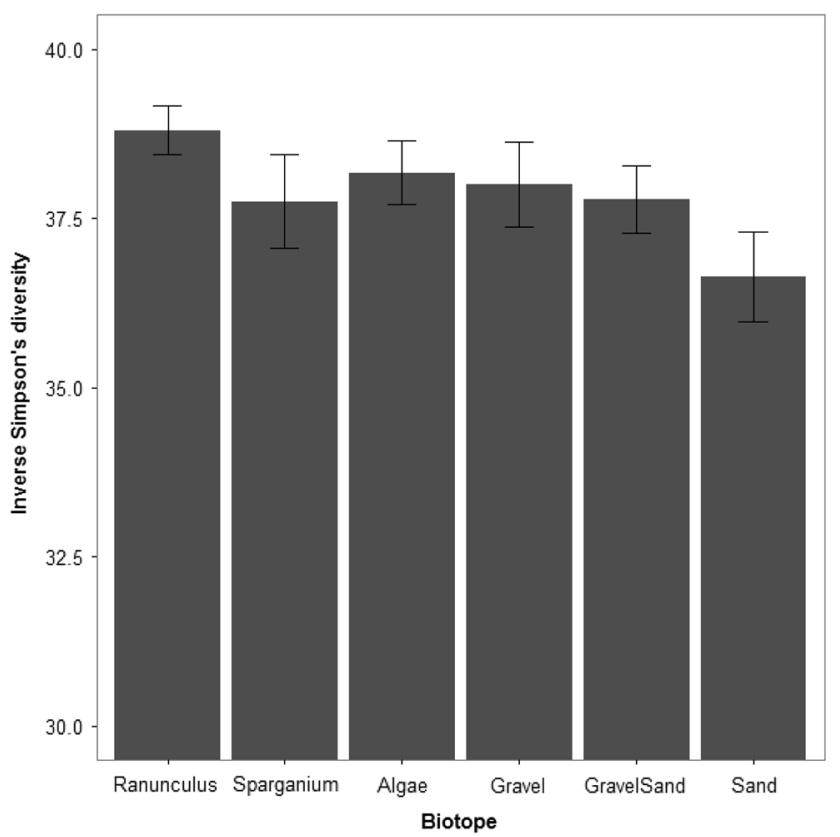

d

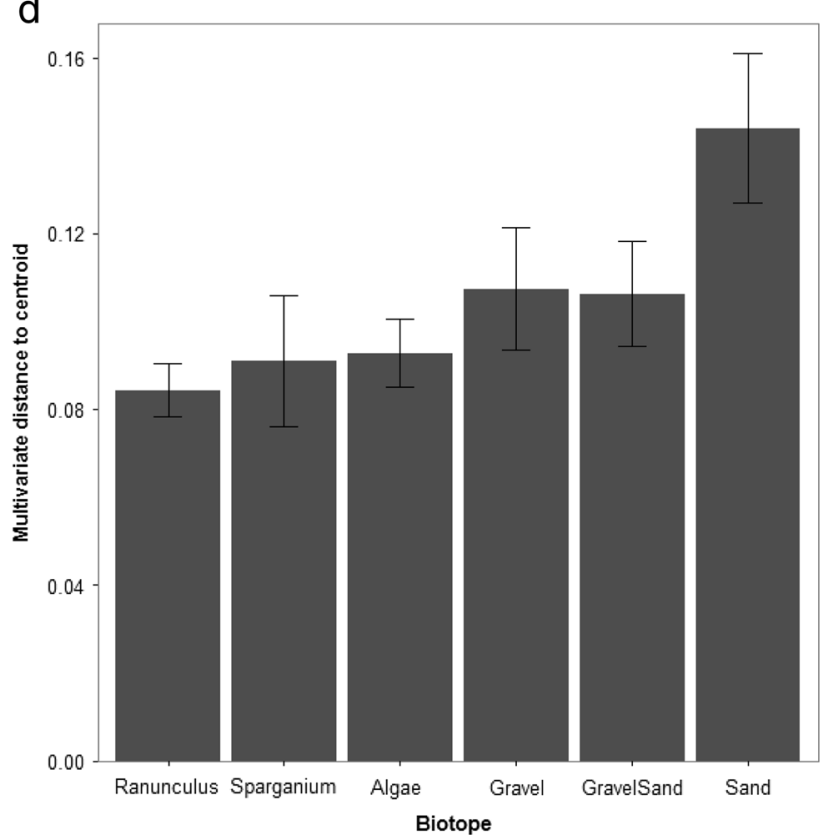

Fig. 3 Alpha-diversity (Inverse Simpson's) and beta-diversity (multivariate dispersion) measures of macroinvertebrate taxonomic and functional trait compositions across different biotopes a Inverse Simpson's diversity measure for taxonomic compositions; b Inverse Simpson's diversity measure for trait compositions; c Multivariate dispersion of taxonomic compositions; d Multivariate dispersion of trait compositions

of environmental conditions and constraints (River Restoration Centre 2013). This study examined three restoration projects which aimed to reinstate a pre-disturbed braided planform by creating a multi-channel system. Such techniques are novel within the UK, as efforts have been historically focused on reworking the structure of a single channel. As such, the restoration projects examined within this study differ drastically from others across the UK which have been the subject of globally recognized post-project appraisals (e.g., Biggs et al. 1998; Pretty et al. 2003; Harrison et al. 2004).

This study found that several macroinvertebrate taxa displayed a reduction in occurrence within restored reaches, specifically the crustaceans Asellidae and Gammaridae. This could be attributed to a reduced amount of coarse organic particulate matter being retained within mineralogical 


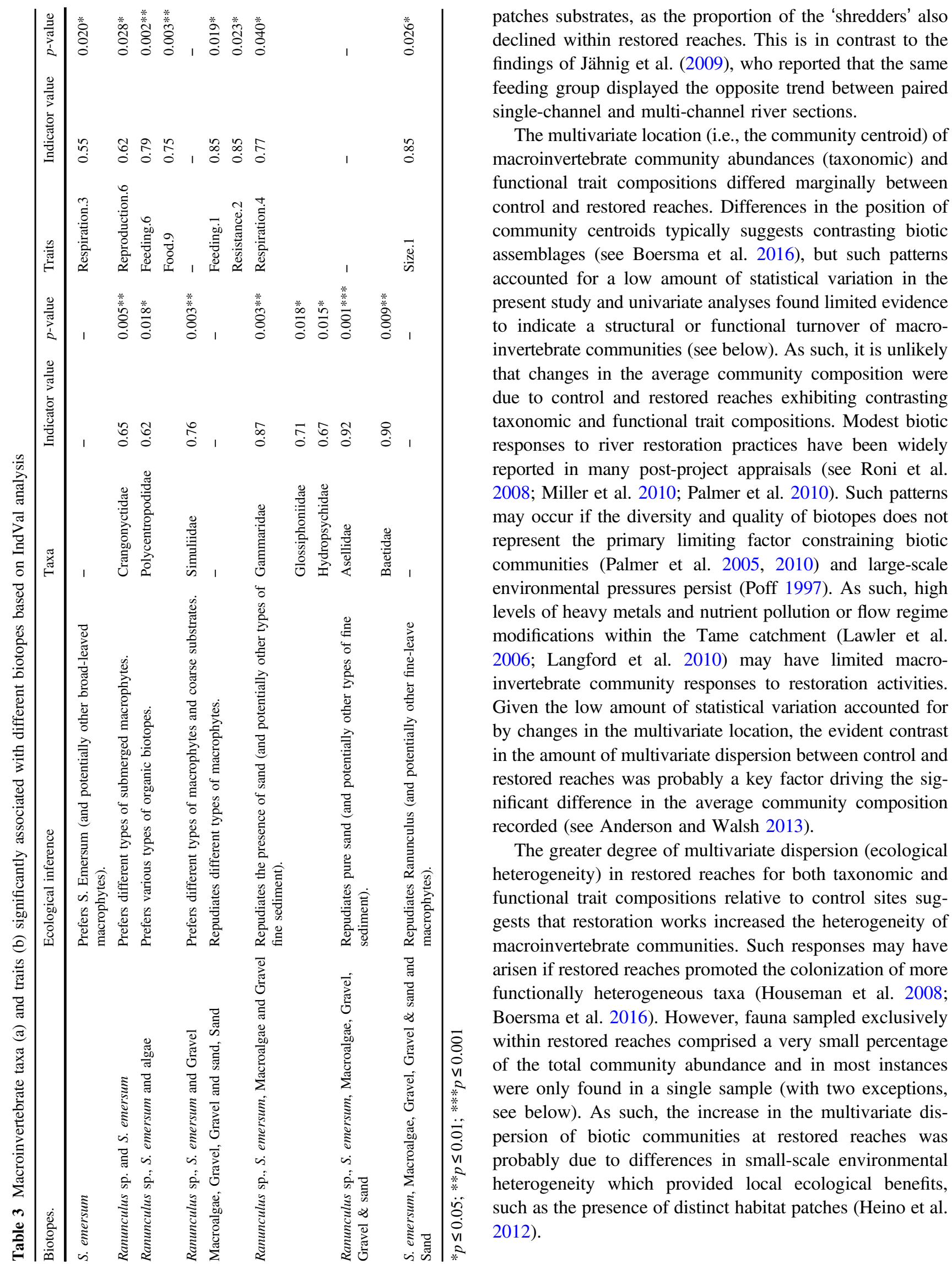




\section{Taxonomic and Functional Trait Compositions Across Different Biotopes}

This study found that sampling macroinvertebrate communities from distinct lotic habitats elucidated detailed ecological responses to river restoration practices, as reported in previous studies (e.g., Jähnig and Lorenz 2008; Verdonschot et al. 2016). While taxa would have been likely to drift between control and restored reaches, sampling from distinct biotopes in this study demonstrated that macroinvertebrates did not widely establish within novel habitats supported by rehabilitated sections of river. For example, those taxa sampled exclusively from restored reaches were numerically rare and recorded within a maximum of one sample from a mineralogical biotope, thus highlighting that the reinstatement of these novel habitats did not facilitate the widespread (re)colonization of "new" taxa. Biotopes have been found to support distinct macroinvertebrate taxonomic compositions in numerous studies (e.g., Armitage et al. 1995; Harper et al. 1998; Buffagni et al. 2000), but few have quantified their functional properties associated with distinct riverine biotopes (but see Demars et al. 2012). This study found that a range of taxa and functional traits were significantly associated with different combinations of biotopes. For example, Sparganium emersum (a broad-leaved macrophyte) was associated with fauna respiring through permanent air stores (plastrons), which often reside in the upper parts of the water column (Chapman et al. 2004). This suggests that the ecology of $S$. emersum, which typically extends from the riverbed through the water column to the surface, provides a niche habitat for taxa possessing this respiratory trait. In addition, the two dominant macrophytes recorded in this study, $S$. emersum and Ranunculus sp. (a fine-leaved macrophyte) were significantly associated with taxa that reproduce by depositing groups of eggs within vegetation. These biotopes were also significantly associated with the non-native amphipod Crangonyctidae, which is in keeping with the findings of Macneil and Dick (2014), who found that this taxon was positively associated with macrophyte cover.

This study highlighted that macroinvertebrate communities varied significantly between biotopes (which accounted for a higher amount of statistical variation than the influence of restoration alone) and indicated that they support different ecological functions, as reported in previous studies (e.g., Harper et al. 1992; Storey and Lynas 2007; Demars et al. 2012). The alpha-diversity of taxonomic compositions was higher in organic biotopes relative to mineralogical habitats, although this was less clear for functional traits (see below). Organic biotopes probably supported a greater number of taxa due to the array of ecological functions provided by such habitats, including them providing a refuge from predators or a platform from which macroinvertebrates can consume detritus (Harper and Everard 1998; Wharton et al. 2006). Sand supported the lowest alpha-diversity measures, as commonly reported within previous studies (e.g., Wood 1998; Larsen and Ormerod 2010; Demars et al. 2012). However, sand exhibited the highest beta-diversity (multivariate dispersion) relative to other biotopes, indicating greater ecological heterogeneity (particularly for the functional properties of communities) existed among individual patches of sand, even if the alpha-diversity within each sample was low.

The identification of biotopes which can support distinct and diverse biotic assemblages may help guide the management and conservation of key habitats during restoration works; this has been advocated as the first step of implementing ecologically effective river restoration strategies (see Roni et al. 2008). This study highlighted that organic biotopes supported the greatest alpha diversity and should be preserved when conducting future management schemes along the studied watercourse. In addition, sampling dominant biotopes provided a basis for understanding biotic responses to river restoration practices by demonstrating that greater ecological heterogeneity existed between mineralogical biotopes (most notably sand). This corroborated the higher amount of multivariate dispersion displayed within restored reaches, which broadly concurs with the findings of Jähnig and Lorenz (2008). Further evidence of this within the present study is provided by the multivariate dispersion not differing significantly between control and restored reaches when only organic biotopes were considered. As such, this study demonstrates the advantages of examining the biotic compositions supported by distinct biotopes as a basis for understanding ecological responses to restoration projects and could be used within future post-project appraisals to better inform management practices.

\section{Utilizing Functional Traits in Post-Project Appraisals}

Functional responses of biotic communities have not been frequently reported within river restoration post-project appraisals (Kail et al. 2015). Such community characteristics could potentially facilitate a priori predictions of ecological responses to river restoration practices (e.g., Lamouroux et al. 2015; Dolédec et al. 2015) and potentially pinpoint where the reinstatement of habitats may yield maximum functionality and biodiversity gains. For example, Verdonschot et al. (2016) found that a functional trait metric based on habitat preferences was more intrinsically linked to habitat heterogeneity induced by river restoration works and attributed this to the creation of specific biotopes (e.g., cobbles and fine particulate organic matter). In addition, Tullos et al. (2009) reported that rehabilitation projects acted as a disturbance, with restored reaches supporting taxa 
which were resistant or resilient to the physical disruption of the riverbed associated with restoration activities, including multivoltinism and high fecundity.

The utilization of functional traits has been limited within the UK thus far (notable exceptions being Demars et al. 2012; White et al. 2017) and their use has been cautioned by some authors due to their potential sensitivity to extraneous factors, such as the inter-correlation between traits (Poff et al. 2006) or the overriding influence of the most abundant taxa (precluding mechanistic ecological associationsPilière et al. 2016). Indeed, Tomanova and UsseglioPolatera (2007) reported that some individual trait responses to environmental variables were difficult to interpret and we experienced similar difficulties in this study, such as taxa that consume vertebrates being significantly associated with organic biotopes. However, numerous trait associations within this study displayed obvious ecological expression, such as macrophytes supporting fauna reproducing by laying groups of eggs in vegetation and taxa displaying an affinity with sand substrates increasing at restored sites (where this biotope widely occurred). This study found that the alpha-diversity of macroinvertebrate functional trait compositions differed less profoundly between organic and mineralogical biotopes relative to taxonomic compositions. This suggests a redundancy of functional traits within organic biotopes, whereby increasing taxonomic diversity will not result in a higher functional diversity and that mineralogical biotopes support a smaller number of taxa capable of performing the same number of functions (Bêche and Resh 2007; Larsen and Ormerod 2010). However, in this study functional trait compositions were more sensitive to multivariate dispersion measures (beta-diversity) compared to taxonomic communities, particularly when considering the difference between biotopes.

In recognition of the need to consider community responses to different environment controls, multivariate analyses have been advocated within the context of restoration ecology (Matthews and Spyreas 2010; Boersma et al. 2016). Such analytical techniques have also been encouraged for analyzing aquatic macroinvertebrate functional traits (Poff et al. 2006) and such approaches have been found to yield comparable statistical outcomes across varying taxonomic resolutions (e.g., Gayraud et al. 2003; Demars et al. 2012). Multivariate dispersion was found to be a key measure of ecological responses in this study as it allowed the heterogeneity (beta-diversity) of macroinvertebrate communities to be quantified (Anderson et al. 2006). Previous studies examining the multivariate dispersion of ecological communities have found that similar results can be obtained using family-level data and/or species-level data (e.g., Terlizzi et al. 2009; Hill et al. 2016), and that finer taxonomic resolutions may not necessarily be required to guide management strategies. It is important that future post-project appraisals should examine the multivariate dispersion alongside average differences in community compositions (i.e., multivariate location-see Anderson and Walsh 2013), as it can be a valuable indicator of ecological responses to changes in habitat compositions (e.g., Heino et al. 2012). Such analyses have rarely been explored within the context of functional traits (see Schmera et al. 2017), but results from this study highlight that the multivariate dispersion of functional traits should be examined within future river restoration post-project appraisals.

Acknowledgements The authors gratefully acknowledge RSPB Middleton Lakes, Tamworth Shooting Ground, as well as Staffordshire and Warwickshire Wildlife Trusts that granted access to sites. Specifically, thanks are extended towards Nick Mott, Tim Haselden and Andrew Crawford for detailed discussions on the restoration works studied in this project. Our gratitude is expressed towards Phillipe Usseglio-Polatera for the provision of the functional traits database, as well as Benoit Demars and Stefano Larsen for comments on the processing of functional trait values. We would like to thank the associate editor and two anonymous reviewers for their valuable comments to help improve the manuscript. Special thanks are also extended to Sophie Nelson, Julie White and Christopher White for their assistance in the field.

\section{Compliance with Ethical Standards}

Conflict of Interest The authors declare that they have no competing interests.

Open Access This article is distributed under the terms of the Creative Commons Attribution 4.0 International License (http://creativecommons.org/licenses/by/4.0/), which permits unrestricted use, distribution, and reproduction in any medium, provided you give appropriate credit to the original author(s) and the source, provide a link to the Creative Commons license, and indicate if changes were made.

\section{References}

Anderson MJ, Ellingsen KE, McArdle BH (2006) Multivariate dispersion as a measure of beta diversity. Ecol Lett 9(6):683-693

Anderson MJ, Walsh DCI (2013) PERMANOVA, ANOSIM, and the Mantel test in the face of heterogeneous dispersions: What null hypothesis are you testing? Ecol Monogr 83(4):557-574

Armitage PD, Pardo I (1995) Impact assessment of regulation at the reach level using macroinvertebrate information from mesohabitats. Regul Rivers: Res Manage 10(2-4):147-158

Armitage PD, Pardo I, Brown A (1995) Temporal constancy of faunal assemblages in 'mesohabitats' - application to management? Archiv für Hydrobiologie 133(3):367-387

Barnes JB, Vaughan IP, Ormerod SJ (2013) Reappraising the effects of habitat structure on river macroinvertebrates. Freshwater Biol 58(10):2154-2167

Bêche LA, Resh VH (2007) Biological traits of benthic macroinvertebrates in California mediterranean-climate streams: longterm annual variability and trait diversity patterns. Fund Appl Limnol/Archiv für Hydrobiologie 169(1):1-23 
Beavan L, Sadler J, Pinder C (2001) The invertebrate fauna of a physically modified urban river. Hydrobiologia 445(1-3): 97-108

Bernhardt ES, Sudduth EB, Palmer MA, Allan JD, Meyer JL, Alexander G, Follastad-Shah J, Hassett B, Jenkinson R, Lave R, Rumps J, Pagano L (2007) Restoring rivers one reach at a time: results from a survey of US river restoration practitioners. Restor Ecol 15(3):482-493

Biggs J, Corfield A, Grøn P, Hansen HO, Walker D, Whitfield M, Williams P (1998) Restoration of the rivers Brede, Cole and Skerne: a joint Danish and British EU-LIFE demonstration project, V-short-term impacts on the conservation value of aquatic macroinvertebrate and macrophyte assemblages. Aquat Conserv 8(1):241-255

Boersma KS, Dee LE, Miller SJ, Bogan MT, Lytle DA, Gitelman AI (2016) Linking multidimensional functional diversity to quantitative methods: a graphical hypothesis-evaluation framework. Ecology 97:583-593

Buffagni A, Crosa GA, Harper DM, Kemp JL (2000) Using macroinvertebrate species assemblages to identify river channel habitat units: an application of the functional habitats concept to a large, unpolluted Italian river (River Ticino, northern Italy). Hydrobiologia 435(1-3):213-225

Chapman LJ, Schneider KR, Apodaca C, Chapman CA (2004) Respiratory ecology of macroinvertebrates in a swamp-river system of East Africa. Biotropica 36(4):572-585

Chevene Fran, Doléadec S, Chessel D (1994) A fuzzy coding approach for the analysis of long-term ecological data. Freshwater Biol 31(3):295-309

Davies C and Edwards F (2011) A coded checklist of macroinvertebrates occurring in Fresh Water in the British Isles. Centre for Ecology and Hydrology. <http://nora.nerc.ac.uk/15232/1/ CEHCodeListOctober2011.pdf $>$. Accessed 20 Feb 2015

De Caceres M and Jansen F (2015) Package "indicspecies" Relationship Between Species and Groups of Sites Version 1.7.5, 1-31

Demars BOL, Kemp JL, Friberg N, Usseglio-Polatera P, Harper DM (2012) Linking biotopes to invertebrates in rivers: Biological traits, taxonomic composition and diversity. Ecol Indic 23:301-311

Dolédec S, Castella E, Forcellini M, Olivier J-M, Paillex A, Sagnes P (2015) The generality of changes in the trait composition of fish and invertebrate communities after flow restoration in a large river (French Rhône). Freshwater Biol 60(6):1147-1161

Ellis PA, Mackay R, Rivett MO (2007) Quantifying urban river-aquifer fluid exchange processes: a multi-scale problem. J Contam Hydrol 91(1-2):58-80

Frissell CA, Liss WJ, Warren CE, Hurley MD (1986) A hierarchical framework for stream habitat classification: viewing streams in a watershed context. Environ Manage 10(2):199-214

Gayraud S, Statzner B, Bady P, Haybachp A, Schöll F, UsseglioPolatera P, Bacchi M (2003) Invertebrate traits for the biomonitoring of large European rivers: an initial assessment of alternative metrics. Freshwater Biol 48(11):2045-2064

Google Earth (2015) <https://earth.google.com> Accessed 26 Sept 2014

Harper D, Everard M (1998) Why should the habitat-level approach underpin holistic river survey and management? Aquat Conserv 8 (4):395-413

Harper D, Smith C, Kemp J, Crosa G (1998) 'The use of 'functional habitats' in the conservation, management and rehabilitation of rivers'. In Bretschko G, Helesic J (eds) Advances in river bottom ecology, Backhuys Publishers, Chichester (UK), p 315-326

Harper DM, Smith CD, Barham PJ (1992) 'Habitats as the building blocks for river conservation assessment'. In: Boon PJ, Calow P, Petts GE (eds) River conservation and management. Wiley, Chichester, pp 311-319
Harrison SSC, Pretty JL, Shepherd D, Hildrew AG, Smith C, Hey RD (2004) The effect of instream rehabilitation structures on macroinvertebrates in lowland rivers. J Appl Ecol 41(6):1140-1154

Harvey GL, Clifford NJ (2008) Distribution of biologically functional habitats within a lowland river, United Kingdom. Aquat Ecosyst Health Manag 11(4):465-473

Heino J, Grönroos M, Ilmonen J, Karhu T, Niva M, Paasivirta L (2012) Environmental heterogeneity and $\beta$ diversity of stream macroinvertebrate communities at intermediate spatial scales. Freshw Sci 32(1):142-154

Hill MJ, Biggs J, Thornhill I, Briers RA, Gledhill DG, White JC, Wood PJ, Hassall C (2016) Urban ponds as an aquatic biodiversity resource in modified landscapes. Glob Chang Biol doi:10. 1111/gcb.13401

Houseman GR, Mittelbach GG, Reynolds HL, Gross KL (2008) Perturbations alter community convergence, divergence, and formation of multiple community states. Ecology 89 (8):2172-2180

Jähnig SC, Brabec K, Buffagni A, Erba S, Lorenz AW, Ofenböck T, Verdonschot PF, Hering D (2010) A comparative analysis of restoration measures and their effects on hydromorphology and benthic invertebrates in 26 central and southern European rivers. J Appl Ecol 47(3):671-680

Jähnig SC, Lorenz AW (2008) Substrate-specific macroinvertebrate diversity patterns following stream restoration. Aquat Sci 70 (3):292-303

Jähnig SC, Lorenz AW, Hering D (2009) Restoration effort, habitat mosaics, and macroinvertebrates-does channel form determine community composition? Aquat Conserv 19 (2): $157-169$

Kail J, Brabec K, Poppe M, Januschke K (2015) The effect of river restoration on fish, macroinvertebrates and aquatic macrophytes: a meta-analysis. Ecol Indic 58:311-321

Kemp JL, Harper DM, Crosa GA (1999) Use of 'functional habitats' to link ecology with morphology and hydrology in river rehabilitation. Aquat Conserv 9(1):159-178

Lamouroux N, Gore JA, Lepori F, Statzner B (2015) The ecological restoration of large rivers needs science-based, predictive tools meeting public expectations: an overview of the Rhône project. Freshwater Biol 60(6):1069-1084

Langford TE, Shaw PJ (2014) Socio-economic, commercial and political factors in river recovery and restoration: has ecology taken a back seat? Freshwater Rev 7:121-138

Langford TE, Shaw PJ, Howard SR, Ferguson AJ, Ottewell D, Eley R (2010) 'Ecological recovery in a river polluted to its sources: the River Tame in the English Midlands'. In: Batty LC, Hallberg KB (eds) Ecology of Industrial Pollution (Ecological reviews). Cambridge University Press, Cambridge, p 255-275

Larsen S, Ormerod SJ (2010) Combined effects of habitat modification on trait composition and species nestedness in river invertebrates. Biol Conserv 143(11):2638-2646

Lawler DM, Petts GE, Foster IDL, Harper S (2006) Turbidity dynamics during spring storm events in an urban headwater river system: the Upper Tame, West Midlands, UK. Sci Total Environ 360(1-3):109-126

Ledger ME, Harris RML, Armitage PD, Milner AM (2009) Realism of model ecosystems: an evaluation of physicochemistry and macroinvertebrate assemblages in artificial streams. Hydrobiologia 617(1):91-99

Lepori F, Palm D, Brännäs E, Malmqvist B (2005) Does restoration of structural heterogeneity in streams enhance fish and macroinvertebrate diversity? Ecol Appl 15(6):2060-2071

Macneil C, Dick JT (2014) Physicochemical tolerance, habitat use and predation are drivers of patterns of coexistence and exclusion among invasive and resident amphipods. Freshw Biol 59 (9):1956-1969 
Matthews JW, Spyreas G (2010) Convergence and divergence in plant community trajectories as a framework for monitoring wetland restoration progress. J Appl Ecol 47(5):1128-1136

Miller SW, Budy P, Schmidt JC (2010) Quantifying macroinvertebrate responses to in-stream habitat restoration: applications of metaanalysis to river restoration. Restor Ecol 18(1):8-19

Oksanen J (2016) "Vegan: ecological diversity" 1-291. <https://cran.rproject.org/web/packages/vegan/vignettes/diversity-vegan.pdf> Accessed 11 Oct 2016

Oksanen J, Blanchet FG, Kindt R, Legendre P, Minchin PR, O'Hara RB, Simpson GL, Solymos P, Stevens MHH, Wagner H (2016) Package "Vegan". Community ecology package Version 2.4.1. $1-291$

Ormerod SJ (2004) A golden age of river restoration science? Aquat Conserv 14(6):543-549

Palmer MA, Bernhardt ES, Allan JD, Lake PS, Alexander G, Brooks S, Carr J, Clayton S, Dahm CN, Follstad Shah J, Galat DL, Loss SG, Goodwin P, Hart DD, Hassett B, Jenkinson R, Kondolf GM, Lave R, Meyer JL, O'Donnell. TK, Pagano L, Sudduth E (2005) Standards for ecologically successful river restoration. J Appl Ecol 42(2):208-217

Palmer MA, Menninger HL, Bernhardt E (2010) River restoration, habitat heterogeneity and biodiversity: a failure of theory or practice? Freshwater Biol 55:205-222

Pilière AFH, Verberk WCEP, Gräwe M, Breure AM, Dyer SD, Posthuma L, Zwart D, Huijbregts MAJ, Schipper AM (2016) On the importance of trait interrelationships for understanding environmental responses of stream macroinvertebrates. Freshwater Biol 61(2):181-194

Poff NL (1997) Landscape filters and species traits: towards mechanistic understanding and prediction in stream ecology. $\mathrm{J}$ North Am Benthol Soc 16(2):391-409

Poff NL, Olden JD, Vieira NK, Finn DS, Simmons MP, Kondratieff BC (2006) Functional trait niches of North American lotic insects: traits-based ecological applications in light of phylogenetic relationships. J North Am Benthol Soc 25 (4):730-755

Pretty JL, Harrison SSC, Shepherd DJ, Smith C, Hildrew AG, Hey RD (2003) River rehabilitation and fish populations: assessing the benefit of instream structures. J Appl Ecol 40 (2):251-265

R Development Core Team (2014) R: A language and environment for statistical computing. R Foundation for Statistical Computing, Vienna

Roni P, Hanson K, Beechie T (2008) Global review of the physical and biological effectiveness of stream habitat rehabilitation techniques. North Am J Fish Manage 28(3):856-890

River Restoration Centre (2013) Manual of river restoration techniques (Update 2), Silsoe, UK. <http://www.therrc.co.uk/manual-riverrestoration-techniques $>$ Accessed 25 Aug 2016

Schmera D, Heino J, Podani J, Erős T, Dolédec S (2017) Functional diversity: a review of methodology and current knowledge in freshwater macroinvertebrate research. Hydrobiologia 787 (1):27-44

Schmera D, Podani J, Erős T, Heino J (2014) Combining taxon-bytrait and taxon-by-site matrices for analysing trait patterns of macroinvertebrate communities: a rejoinder to Monaghan and Soares. Freshwater Biol 59(7):1551-1557
Schmera D, Podani J, Heino J, Erôs Tibor, Poff NL (2015) A proposed unified terminology of species traits in stream ecology. Freshwater Sci 34(3):823-830

Storey AW, Lynas J (2007) Application of the functional habitat concept to the regulated Lower Ord River, Western Australia, Part I, macroinvertebrate assemblages. Hydrobiologia 592(1):499-512

Tachet, H, Bournaud, M, Richoux, P and Usseglio-Polatera, P (2010) Invertébrés d'eau douce: systématique, biologie, écologie. CNRS Editions, Paris

Terlizzi A, Anderson MJ, Bevilacqua S, Fraschetti S, WłodarskaKowalczuk M, Ellingsen KE (2009) Beta diversity and taxonomic sufficiency: do higher-level taxa reflect heterogeneity in species composition? Divers Distrib 15(3):450-458

Tickner D, Armitage PD, Bickerton MA, Hall KA (2000) Assessing stream quality using information on mesohabitat distribution and character. Aquat Conserv 10(3):179-196

Tomanova S, Usseglio-Polatera P (2007) Patterns of benthic community traits in neotropical streams: relationship to mesoscale spatial variability. Fund Appl Limnol / Archiv f ür Hydrobiologie 170(3):243-255

Tonkin JD, Stoll S, Sundermann A, Haase P (2014) Dispersal distance and the pool of taxa, but not barriers, determine the colonisation of restored river reaches by benthic invertebrates. Freshwater Biol 59(9):1843-1855

Tullos DD, Penrose DL, Jennings GD, Cope WG (2009) Analysis of functional traits in reconfigured channels: implications for the bioassessment and disturbance of river restoration. J North Am Benthol Soc 28(1):80-92

Usseglio-Polatera P, Bournaud M, Richoux P, Tachet, H (2000) Biological and ecological traits of benthic freshwater macroinvertebrates: relationships and definition of groups with similar traits. Freshwater Biol 43(2):175-205

Verdonschot RC, Kail J, McKie BG, Verdonschot PF (2016) The role of benthic microhabitats in determining the effects of hydromorphological river restoration on macroinvertebrates. Hydrobiologia 769(1):55-66

Webster P, West JR, Gurnell AM, Petts GE, Sadler JP, Forster CF (2001) Development, flood risk and the urban environment: experiences from the River Tame. Water Environ J 15 (3): $167-173$

Wharton G, Cotton JA, Wotton RS, Bass JA, Heppell CM, Trimmer M, Sanders IA, Warren LL (2006) Macrophytes and suspensionfeeding invertebrates modify flows and fine sediments in the Frome and Piddle catchments, Dorset (UK). J Hydrol 330 (1):171-184

Wickham H and Chang W (2016). Package "ggplot2". Create Elegant Data Visualisations Using the Grammar of Graphics. Version 2.2.1. 1-189

White JC, Hannah DM, House A, Beatson SJV, Martin A, Wood PJ (2017) Macroinvertebrate responses to flow and stream temperature variability across regulated and non-regulated rivers. Ecohydrology 10(1):e1773. 1-21

Wood PJ (1998) 'Reach-scale mesohabitat variaitons in a small chalk stream under low flow conditions'. In Bretschko $G$ and Helesic J (Eds) Advances in river bottom ecology, Backhuys Publishers, Leiden (The Netherlands), 31-38 